\title{
Clinical correlates of different forms of endolymphatic hydrops
}

\author{
Hesham Mohammed Taha', Ihab Nada², Maha Mohammed Alagamy ${ }^{3}$ and Tayseer Taha Abdel Rahman ${ }^{{ }^{*}}$ (I)
}

\begin{abstract}
Background: The aim of this study is to explore the different kinds of endolymphatic hydrops and the sensitivity of vestibular evoked myogenic potentials (VEMP) and electrocochleography in their diagnosis. Three groups of patients were selected according to the diagnosis, definitive MD (DMD), cochlear MD (CMD), and recurrent vestibulopathy (RV) groups. A basic audiological evaluation was carried out. It included pure tone audiometry, speech audiometry, acoustic immittancemetry testing and electrocochleography, cervical VEMP (c-VEMP), and ocular VEMP (o-VEMP).

Results: The overall sample was 40 cases, 13 with DMD, 10 with CMD, and 17 with RV. The mean age is variable between groups ( $p$-value $<0.001)$ with the highest in the DMD group $(38.3 \pm 7.4$ years) and the lowest in the CMD group ( $25.2 \pm 4.6$ years). The male to female ratio is variable between groups of the study ( $p$-value $=0.03$ ) with the highest ratio 9:4 in the DMD group. There was a significant difference between groups $(p<0.001)$ regarding dizziness. Asymmetric response of c-VEMP was seen in nine (69.2\%) of DMD cases, in 14 (82.4\%) of RV cases, and only in three (30\%) of CMD cases ( $p$-value $<0.001)$. Low amplitude of o-VEMP was seen in $11(84.6 \%)$ of DMD cases, 9 (90\%) of CMD cases, 15 (88.2\%) of RV cases, and only two (25\%) of normal cases ( $p$-value $=0.002)$. A significant difference was found between definitive and cochlear Meniere's as regards o-VEMP inter-aural amplitude difference (IAD) ( $p$-value $=0.032)$ only. There was a significant positive strong correlation between age and EcochG SP/AP ratio left ear, o-VEMP IAD, and o-VEMP left ear n1. In addition, there is a significant positive weak correlation between duration and EcochG SP/AP ratio left ear and c-VEMP left ear $n 1$.
\end{abstract}

Conclusions: Asymmetric response of c-VEMP can be used as a diagnostic tool to differentiate different kinds of MD: $\mathrm{DMD}, \mathrm{RV}$, and CMD.

Keywords: Meniere's disease, Ocular vestibular evoked myogenic potentials, Cervical vestibular evoked myogenic potentials, Definitive Ménière's, Cochlear Ménière's, Recurrent vestibulopathy

\section{Background}

Meniere's disease (MD), one of the most common disorders of the inner ear, is thought to be an idiopathic progressive disease. It is caused by hair cell degeneration in the cochlea and vestibule. Prosper Meniere was the scientist who described it; thus, it was named after him. While on the other hand Ménière's syndrome can be secondary to various processes interfering with the normal

\footnotetext{
*Correspondence: tayseerhesham2005@gmail.com

1 Department of ENT: Audiology Unit, Faculty of Medicine, Ain Shams University, Villa $4 \backslash 7$ E, Compound Calimera, Shorouk City, Cairo, Egypt Full list of author information is available at the end of the article
}

production or resorption of the endolymph like trauma, viral vestibular ganglionitis, and genetic predisposition, also, it is thought to be caused by pathologies of the stria vascularis that can result in its symptoms $[1,2]$.

The excess hydraulic pressure within the inner ear's endolymphatic system causes unstable hearing loss, occasional vertigo, tinnitus or ringing in the ears, and aural fullness. The term endolymphatic hydrops can be synonymously used with MD and Ménière's syndrome [3].

Definitive Meniere is diagnosed by the following criteria: two or more episodes of vertigo that lasted at least 20 min in addition to audiometrically documented hearing 
loss that has been documented at least once. Tinnitus and/or aural fullness are also symptoms that are added.

Cochlear Meniere's or atypical Meniere's: in this condition, the patient suffers only from the cochlear group of symptoms of Meniere's disease without the vertiginous symptoms at the beginning. Later on, definitive Meniere's disease may develop [4].

Recurrent vestibulopathy: This clinical category describes the recurrent attacks of vertigo similar to Meniere's disease but without the presence of hearing loss or tinnitus or even aural fullness. The vertiginous attacks are usually of sudden onset. However, it was proved that it develops into full-blown Meniere's disease eventually, instead of being a separate entity on its own [5].

Ocular vestibular evoked myogenic potentials (o-VEMP) and cervical vestibular evoked myogenic potentials (c-VEMPs) are both elicited by acoustic stimulation of the vestibular organs. The response is measured in muscle EMG. The o-VEMP is recorded by placing recording electrodes below the eyes and maintaining an upward gaze during recording, forcing the inferior oblique muscle closer to the recording electrode. One major difference between the o-VEMP and c-VEMP is that the o-VEMP is a contralateral response whereas the c-VEMP is ipsilateral. In addition, the c-VEMP is an inhibitory response and the o-VEMP is an excitatory response. It has been also thought that the o-VEMP is mainly mediated by utricular stimulation while the c-VEMP is a saccular response [6].

There is little information in literature about different categories of endolymphatic hydrops: definitive Ménière's (DMD), cochlear Ménière's (CMD), and recurrent vestibulopathy (RV). Thus, this study was designed to explore the sensitivity of VEMP in the diagnosis of the different kinds of endolymphatic hydrops compared to findings of electrocochleography.

\section{Methods}

The current study was a cross-sectional study that included all patients aged 18 years or more with endolymphatic hydrops of any degree who came to the outpatient clinic during the period from March 2018 and March 2020. All participants included in the study have provided an informed consent. The Ethical Review Board has approved this study. The patients were divided into three groups and were selected according to the diagnosis: group 1: patients with DMD, group 2: patients with $\mathrm{RV}$, and group 3: patients with CMD.

Exclusion criteria were patients with sudden SNHL, retrocochlear pathology, neurological disorders, and any history suggestive of vestibular neuritis; any patients with a history suggestive of head trauma; or patients with any history suggestive of benign positional paroxysmal attacks.

- Full history was taken from all patients

- Basic audiological evaluations were carried out. It included the following procedures:

Pure tone audiometry and speech audiometry: a twochannel audiometer (AC 40) was used.

Acoustic immittancemetry testing: it included tympanometry and acoustic reflex threshold measurement.

\section{- Video nystagmography (VNG)}

The test protocol included spontaneous nystagmus, gaze test, oculomotor tests, positioning test (Dix-Hallpike), positional nystagmus, and caloric testing. Video nystagmography (VNG) was carried out using Micromedical Tech, Meta 4 software version 4.5.

\section{- Electrocochleography}

Non-invasive tympanic membrane electrocochleography was carried out using Otopront evoked potential system. The active electrode was a gold-plated triptode by Biologic Corporation. Sound delivery system was an insert phone placed in the external auditory canal. The other two electrodes were placed at the contralateral mastoid and the forehead to serve as negative and ground electrodes, respectively. Stimuli consisted of $100-\mu$ s clicks generated at a rate of 7.1 pulses/s at $90 \mathrm{db}$ nHL. Alternating polarity was used. A system bandpass of $10 \mathrm{HZ}$ to 1.5 $\mathrm{kHZ}$ was utilized. Analysis of the waveforms was carried out by measuring the amplitude of the SP from the prestimulus baseline to the shoulder of the preceding edge of the AP.

- Otolith function assessment was carried out in the form of:

Cervical vestibular evoked myogenic potentials (c-VEMP): The subject was in a sitting position and was instructed to rotate his head to the opposite side of the stimulated ear and to maintain muscle contraction. Otopront evoked potential system was used. The average of two runs was taken for the amplitude and latencies and compared to the values of the control group. Latencies of p13 and N23 were measured. $\mathrm{P} 13$ is the first positive peak of c-VEMP and $\mathrm{n} 23$ is the first negative peak following p13. For the evaluation of the amplitude, the inter-peak p13-n23 amplitude was measured. The adult normative data of Audiology Unit Ain Shams was $15.5( \pm 2.3)$ and $23.6( \pm 2.9) \mathrm{ms}$ for the 
latency of the p13 and n 23 waves, respectively. For air conduction stimulus, p13-n23 inter-amplitude was 112 $( \pm 67.5) \mathrm{ms}$.

Ocular vestibular evoked myogenic potentials (o-VEMP): The subject was in the sitting position and was instructed to look upward to a small fixed target more than $2 \mathrm{~m}$. The vertical eye position was at an angle of approximately $30-35^{\circ}$ above the horizontal line. The surface electrodes were placed at three $\mathrm{mm}$ below the eye and centered beneath their pupil not the inferior ocular muscle, a reference electrode was placed on the chin, and the ground impedance was kept under $5 \Omega$ as $n 1$ responses are best recorded from the extra-ocular muscles slightly below the eye contralateral to stimulation $[6,7]$. O-VEMP testing was recorded bilaterally with the $500-\mathrm{Hz}$ tone burst stimulus, rise/fall time of $2 \mathrm{~ms}$, and a plateau of $1 \mathrm{~ms}$. The repletion rate was $5 / \mathrm{s}$ at $90-\mathrm{dB} \mathrm{nHL}$ intensity using an insert receiver. The response from each side was amplified by band pass filter $(10-1500 \mathrm{~Hz})$. Two hundred sweeps were averaged with a window of $50 \mathrm{~ms}$. At least two consecutive averages were recorded from each side to verify reproducibility. The average of two runs was taken for the amplitude and latencies were compared to the values well known. Latencies of $n 1$ and $p 1$ were measured. N1 is the first negative peak of o-VEMP and $\mathrm{p} 1$ is the first positive peak following $\mathrm{n} 1$. For evaluation of the amplitude, n1-p1 inter amplitude was measured. The latencies of the $\mathrm{n} 1$ and $\mathrm{p} 1$ from the adult normative data were $11.1( \pm 0.4)$ and $15.9( \pm 0.4)$ ms respectively for air conduction stimuli. N1-P1 inter-amplitude was $14.6( \pm 4.80)$.

\section{Statistical analysis}

The patients were grouped into three groups. The three groups were compared for all demographic variables as well as clinic-pathologic variables and for all tests. Recorded data were coded, entered, cleaned, and analyzed using the statistical package for social sciences, version 25.0 (SPSS Inc., Chicago, IL, USA). Quantitative data were expressed as mean \pm standard deviation (SD) or median and interquartile range (IQR). Qualitative data were expressed as frequency and percentage. Chi-square $\left(x^{2}\right)$ test of significance or ANOVA was used in order to compare proportions between the qualitative parameters, and the Student $t$-test was used for the numerical parametric data. Non-parametric statistical tests were applied whenever indicated. Post hoc tests were made for further comparisons. The confidence level was set to $95 \%$ and the margin of error accepted was set to $5 \%$. So, the $p$-value was considered significant if $\leq 0.05$. The correlation coefficient was calculated.

\section{Results}

The study included 40 patients with different degrees of MD: 13 with DMD, 10 with CMD, and 17 with RV. In addition, the study included eight normal control subjects. Therefore, the total sample was 48 subjects. The study included 40 patients with different types of Meniere's disease: 13 with definitive Meniere's, 10 with cochlear Meniere's, and 17 with recurrent vestibulopathy. In addition, the study included eight normal control subjects. Therefore, the total sample was 48 subjects.

The mean age was $32.9 \pm 6.8$ years with a minimum age of 20 and a maximum of 47 years. In addition, the mean age is variable between groups $(p$-value $<0.001)$ with the highest in the definitive Meniere's group (38.3 \pm 7.4 years) and the lowest in the cochlear Meniere's group $(25.2 \pm 4.6$ years $)$.

\section{Demographic data}

Regarding gender, there is a significant difference in gender between groups $(p=0.03)$. Post hoc testing revealed that male gender is more prevalent in the definitive Meniere's group than in the other groups $(p=0.002)$. Female gender is more prevalent in the recurrent vestibulopathy group $(p=0.009)$. There was a highly significant difference in age between groups $(p<0.001)$. Those with definitive Meniere's tend to be older than other groups. In addition, those with cochlear Meniere's tend to be younger than other groups.

\section{Main complaint}

Regarding complaint, there is a significant difference among groups $(p<0.001)$. Post hoc testing revealed that vertigo is more prevalent in the definitive recurrent vestibulopathy than other groups $(p=0.002)$. Hearing loss is more prevalent in the cochlear Meniere's group $(p<$ $0.001)$.

\section{Aural fullness, tinnitus, and history of Tumarkin crisis}

Regarding aural fullness, there is a significant difference among the groups $(p<0.001)$. Post hoc testing revealed that aural fullness is less prevalent in the cochlear Meniere's group $(p<0.001)$ than in the other groups.

Regarding tinnitus, there is a significant difference among the groups $(p=0.001)$. Post hoc testing revealed that tinnitus is less prevalent in the cochlear Meniere's group $(p<0.001)$ than in other groups.

Regarding history of Tumarkin crisis, there is a significant difference between the groups as one of them is $0 \%$ and the others are $38.5 \%$ and $23.5 \%$.

\section{Laterality of the disease}

Five cases (38.5\%) of definitive Meniere's and six cases $(60 \%)$ of cochlear Meniere's have had unilateral affection, 
while 16 cases (94.1\%) of recurrent vestibulopathy have had unilateral affection. There is a significant difference between groups with regard to laterality of the condition $(p<0.001)$. Post hoc tests showed that unilateral affection is more in the recurrent vestibulopathy group and cochlear Meniere's while bilateral affection is more in the definitive Meniere's group $(p<0.001)$.

There is a significant difference among groups with regard to the duration $(p=0.011)$. Post hoc tests showed that definitive Meniere's group has a significantly longer duration than the other groups $(p<0.001)$.

\section{Family history}

Regarding positive family history, there is a significant difference between groups $(p<0.001)$. Post hoc testing revealed that positive family history is not related to cochlear Meniere's $(p<0.001)$.

The right ear audiogram is significantly $(p<0.001)$ affected in the definitive Meniere's and the cochlear Meniere's groups than other groups especially at 250, 500 , and $1000 \mathrm{~Hz}$ frequencies.

There is a highly significant difference $(p<0.001)$ among the three groups regarding the left ear and right ear speech discrimination score.

The post hoc Bonferroni test showed that the scores are significantly $(p<0.001)$ lower in the definitive Meniere's group than both in cochlear Meniere's group and the recurrent vestibulopathy group.

All cases of definitive Meniere's 13 (100\%) and cochlear Meniere's 10 (100\%) have had SNHL.

\section{Electrocochleography}

Non-invasive tympanic membrane electrocochleography was performed for all cases. A value above $\geq 0.42$ was considered abnormal.

There was a highly significant $(p<0.001)$ difference in the mean left ear SP/AP ratio between groups. The post hoc Bonferroni test for multiple comparisons revealed a significant difference between definitive and cochlear Meniere's $(p<0.001)$ and between the definitive Meniere's group and the recurrent vestibulopathy group $(p=0.003)$.

\section{Vestibular assessment: video-nystagmography (VNG)}

Classic video-nystagmography (VNG) test battery was performed searching for spontaneous, gaze-evoked positional and positioning nystagmus. Oculomotor test battery included regular random saccade testing, together with eye tracking and optokinetic tests. Bithermal caloric test was performed.

All cases have had no spontaneous nystagmus, negative gaze test, saccade test, tracking test, optokinetic test, and
Dix-Hallpike test. Positional nystagmus was positive in some cases.

Caloric test is comparable between all study groups ( $p$-value $>0.05)$, as shown in Table 9.

\section{Otolith function assessment \\ Cervical vestibular evoked myogenic potentials (c-VEMP)}

Asymmetric response of C-VEMP was seen in nine $(69.2 \%)$ of definitive Meniere's cases, in $14(82.4 \%)$ of recurrent vestibulopathy cases, and only in three (30\%) of cochlear Meniere's cases $(p$-value $<0.001)$, as shown in Table 10

There is a highly significant $(p<0.001)$ difference in the mean of c-VEMP between groups. Post-hoc Bonferroni test for multiple comparisons revealed a significant difference between the definitive and normal groups $(p<$ $0.001)$.

There is a significant difference ( $p$-values $<0.001)$ in $\mathrm{p} 1$ and $\mathrm{n} 1$ latencies in the right ear between the study groups, as shown in Table 11. Post hoc testing showed that in the right ear P1 latency, the difference is between recurrent vestibulopathy and both definitive Meniere's $(p<0.001)$ and cochlear Meniere's $(p<0.001)$. In addition, in the right ear N1 latency, the difference is between recurrent vestibulopathy and both definitive Meniere's ( $p$ $<0.001)$ and cochlear Meniere's $(p=0.024)$.

c-VEMP IAD was significantly variable between groups $(p=0.028)$, and it was $6(46 \%)$ in the DMD, $7(70 \%)$ in the CMD, and 7 (41\%) in the RV groups. Post hoc testing revealed non-significant results.

\section{Ocular vestibular evoked myogenic potentials (o-VEMP)}

Low amplitude of o-VEMP was seen in $11(84.6 \%)$ of definitive Meniere's cases, 9 (90\%) of cochlear Meniere's cases, and $15(88.2 \%)$ of recurrent vestibulopathy cases ( $p$-value $=0.002)$. Latencies of $\mathrm{n} 1$ and $\mathrm{p} 1$ were measured in right and left ear in all cases.

There is a significant difference in right ear $\mathrm{p} 1$ ( $p$-values $=0.007)$ and left ear $\mathrm{p} 1$ ( $p$-values $=0.027)$ latencies among the study groups, as shown in Table 11. Post hoc testing showed no differences among groups.

\section{Inter-aural amplitude difference (IAD) of o-VEMP}

There is a significant difference in right ear $\mathrm{p} 1(p$-values $=0.007)$ and left ear p1 ( $p$-values $=0.027$ ) latencies between the study groups, as shown in Table 11. Post hoc testing showed no differences between groups.

\section{Duration of symptoms in relation to laterality}

The duration of symptoms was not significantly ( $p=$ 0.068 ) different according to laterality of the condition. The median (IQR) duration was 12.0 (2.0) years in the unilateral versus 12.0 (24) in the bilaterally affected cases. 


\section{Correlations between age, duration, and test findings}

There is a significant positive strong correlation between age and ECochG SP/AP ratio left ear, OVEMP IAD, and OVEMP left ear N1. In addition, there is a significant positive correlation between duration and ECochG SP/AP ratio left ear and between disease duration and CVEMP left ear N1.

\section{Sensitivity and specificity of c-VEMP, o-VEMP, and ECochG}

ECoch is more sensitive and more specific than both c-VEMP and o-VEMP in all categories of endolymphatic hydrops. Ocular VEMP is the least sensitive test in the diagnosis of all types of endolymphatic hydrops. Cervical VEMP has moderate sensitivity in the diagnosis of definitive Meniere's disease, but low sensitivity in both cochlear Meniere and recurrent vestibulopathy. Electrocochleography is the most sensitive test in the diagnosis of all types of endolymphatic hydrops.

o-VEMP IAD was significantly variable between groups $(p=0.018)$, and it was $0.39 \pm 0.08$ in the DMD, $0.17 \pm$ 0.06 in the CMD, and $0.35 \pm 0.07$ in the RV groups. Post hoc testing showed no differences between groups. Post hoc tests for multiple comparisons revealed a significant difference between definitive and cochlear Meniere's as regards o-VEMP IAD $(p=0.032)$ only.

\section{Discussion}

This study was conducted on 40 patients with different degrees of severity of endolymphatic hydrops:

- Thirteen patients with definitive Meniere's disease: Those patients had idiopathic endolymphatic hydrops with the classic tetrad of Meniere's disease, which is at least two episodic vertiginous spells lasting $20 \mathrm{~min}$ or longer, tinnitus, ear fullness, and fluctuating hearing loss [8].

- Ten patients with cochlear Meniere's disease: Those were patients suffering from fluctuating sensorineural hearing loss with tinnitus but no vertigo.

- Seventeen patients with recurrent vestibulopathy: Those were a group of patients with a history of more than a single episode of vertigo, and the duration of the vertigo was characteristic of that occurring with hydrops, but without auditory or neurological symp- toms or signs. This was also identified by Park et al. in a study that revealed that recurrent vestibulopathy was defined as a disease characterized by the occurrence of more than a single episode of vertigo of duration characteristic of endolymphatic hydrops but without auditory or clinical neurological symptoms or signs. Also, they found that recurrent vestibulopathy should be always considered with the patients complaining of recurrent episodic vertigo [9].

In this study, there was a highly significant difference in age among groups. Those with definitive Meniere's were found to be older than other groups. In addition, those with cochlear Meniere's were found to be younger than other groups. These findings agreed with Schaaf et al. who reported that patients with definitive Meniere's were older than the patients from the other two groups known as recurrent vestibulopathy and cochlear Meniere's as those patients may develop into the full-blown picture of definitive Meniere's disease later in life [10].

As regards gender prevalence, this study revealed that there was a significant difference in gender prevalence among the groups. Female gender was more prevalent in the definitive Meniere's disease group than the other two groups, as shown in Table 1. These findings agreed with Simo et al. who reported that Meniere's disease was found to be higher among females with a rate of 84 per 100,000 compared to a rate of 56 per 100,000 among males [11].

Regarding family history, the study revealed that there was a significant difference among the groups, as it was strong in the definitive Meniere group and in the recurrent vestibulopathy but not in the cochlear Meniere group, as shown in Fig. 1. This study agreed with Requena et al., who reported that MD was a complex trait and multiple genes and environmental factors contributed to its development. The aggregation of a disease in families was the first observable clue for an underlying genetic susceptibility [12]. The findings of Lopez et al. agreed with this study that revealed they found that MD definitely had a genetic prevalence and also that family history of SNHL, migraine, or recurrent vertigo in several members of the family would justify a

Table 1 Demographic data

\begin{tabular}{lllll}
\hline & $\begin{array}{l}\text { Definitive Meniere's, } \\
\boldsymbol{N}=\mathbf{1 3}\end{array}$ & $\begin{array}{l}\text { Cochlear Meniere's, } \\
\boldsymbol{N}=\mathbf{1 0}\end{array}$ & $\begin{array}{l}\text { Recurrent vestibulopathy, } \\
\boldsymbol{N}=\mathbf{1 7}\end{array}$ & $\begin{array}{l}\boldsymbol{p} \text {-value } \\
\text { Male:female ratio }\end{array}$ \\
Age, years, mean $\mathbf{n}$ SD & $9: 4$ & $3: 7$ & $3: 14$ & 0.03 \\
Positive family history & $38.3 \pm 7.4$ & $25.2 \pm 4.6$ & $33.8 \pm 3.6$ & $<0.001$ \\
\hline
\end{tabular}




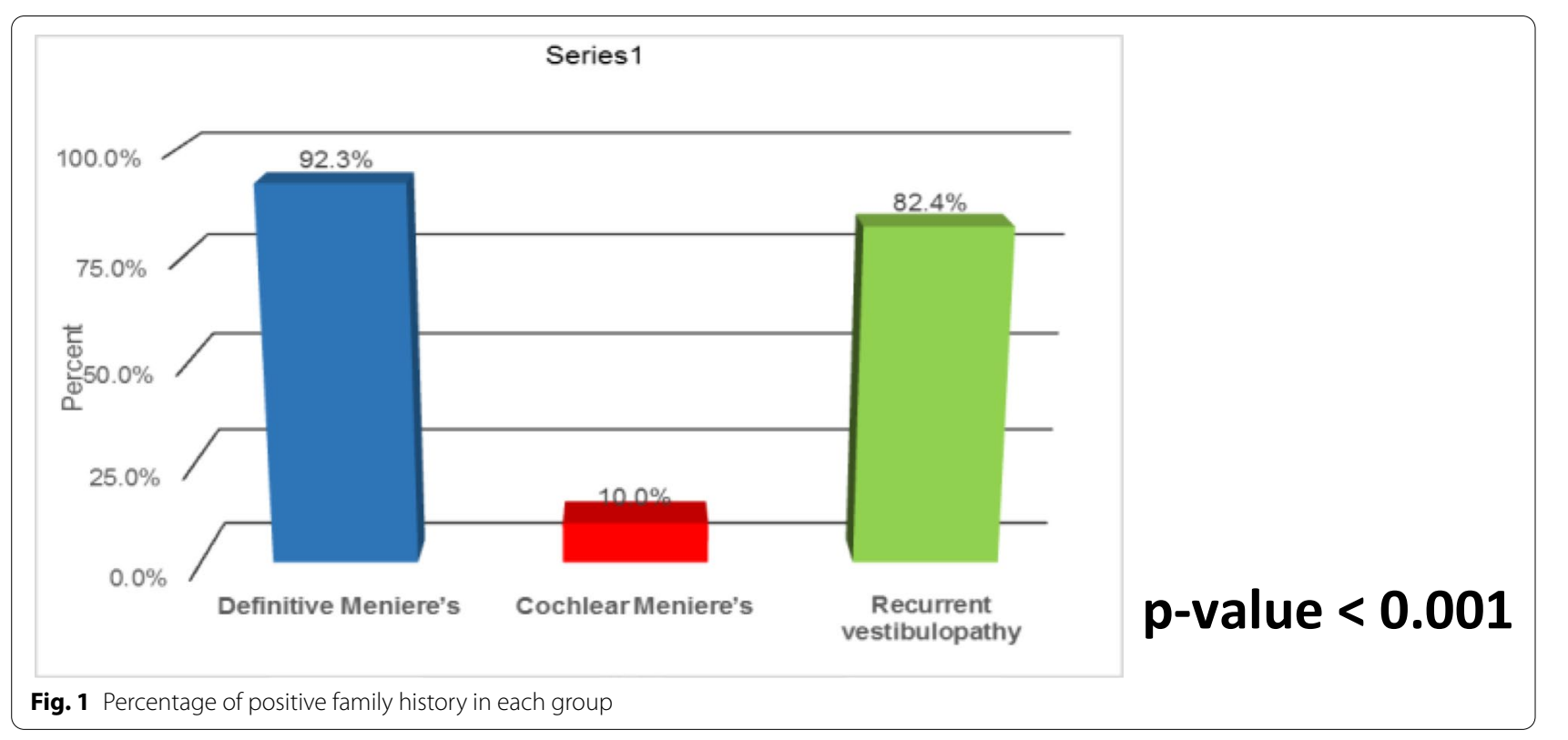

familial investigation of these patients to confirm if any of them fulfill diagnostic criteria for MD [13].

As expected, there was a significant difference among the groups; it was revealed that vertigo was more prevalent in the definitive Meniere and recurrent vestibulopathy than other groups as shown in Table 2. In contrary, hearing loss was more prevalent in the cochlear Meniere's group, as shown in Figs. 2 and 3.

Regarding aural fullness, there is a significant difference among the groups as shown in Table 2 which found that aural fullness was less prevalent in the cochlear Meniere's group than the other groups, as aural fullness usually is a result of the more permanent hydrops that result later in the definitive Meniere's stage of the disease [14].

Regarding tinnitus, there is a significant difference among the groups also as shown in Table 2. It was revealed that tinnitus was less prevalent in the cochlear Meniere's group than other groups and this agreed with Huppert et al., as they stated that the disease is still at its early stage not prevailing all of its features [14].

Regarding history of Tumarkin crisis, there is no significant difference among the groups as shown in Table 2. Huppert et al. also revealed in their study that drop attacks were found to occur early or late in the course

Table 2 Clinical characteristics of cases

\begin{tabular}{|c|c|c|c|c|}
\hline & $\begin{array}{l}\text { Definitive Meniere's, } \\
N=13\end{array}$ & $\begin{array}{l}\text { Cochlear Meniere's, } \\
N=10\end{array}$ & $\begin{array}{l}\text { Recurrent vestibulopathy, } \\
N=17\end{array}$ & $p$-value \\
\hline \multicolumn{5}{|l|}{ Main complaint } \\
\hline Hearing loss & $1(7.7 \%)$ & $10(100.0 \%)$ & $0(0.0 \%)$ & $<0.001$ \\
\hline Dizziness & $12(92.3 \%)$ & $0(0.0 \%)$ & $17(100.0 \%)$ & \\
\hline \multicolumn{5}{|l|}{ Dizziness } \\
\hline Normal & $0(0.0 \%)$ & $9(90.0 \%)$ & $0(0.0 \%)$ & $<0.001$ \\
\hline Sense of rotation of surrounding & $3(23.1 \%)$ & $0(00.0 \%)$ & $8(47.1 \%)$ & \\
\hline Sense of imbalance & $8(61.5 \%)$ & $0(0.0 \%)$ & $9(52.9 \%)$ & \\
\hline Sense of self rotation & $2(15.4 \%)$ & $0(0.0 \%)$ & $0(0.0 \%)$ & \\
\hline Aural fullness & $13(100.0 \%)$ & $1(10.0 \%)$ & $16(94.1 \%)$ & $<0.001$ \\
\hline Tinnitus & $13(100.0 \%)$ & $0(00.0 \%)$ & $15(88.2 \%)$ & 0.001 \\
\hline History of Tumarkin crisis & $5(38.5 \%)$ & $0(0.0 \%)$ & $4(23.5 \%)$ & 0.09 \\
\hline \multicolumn{5}{|l|}{ Laterality, $n(\%)$} \\
\hline Unilateral & $5(38.5 \%)$ & $6(60 \%)$ & $16(94.1 \%)$ & $<0.001$ \\
\hline Bilateral & $8(61.5 \%)$ & $4(40 \%)$ & $1(5.9 \%)$ & \\
\hline
\end{tabular}




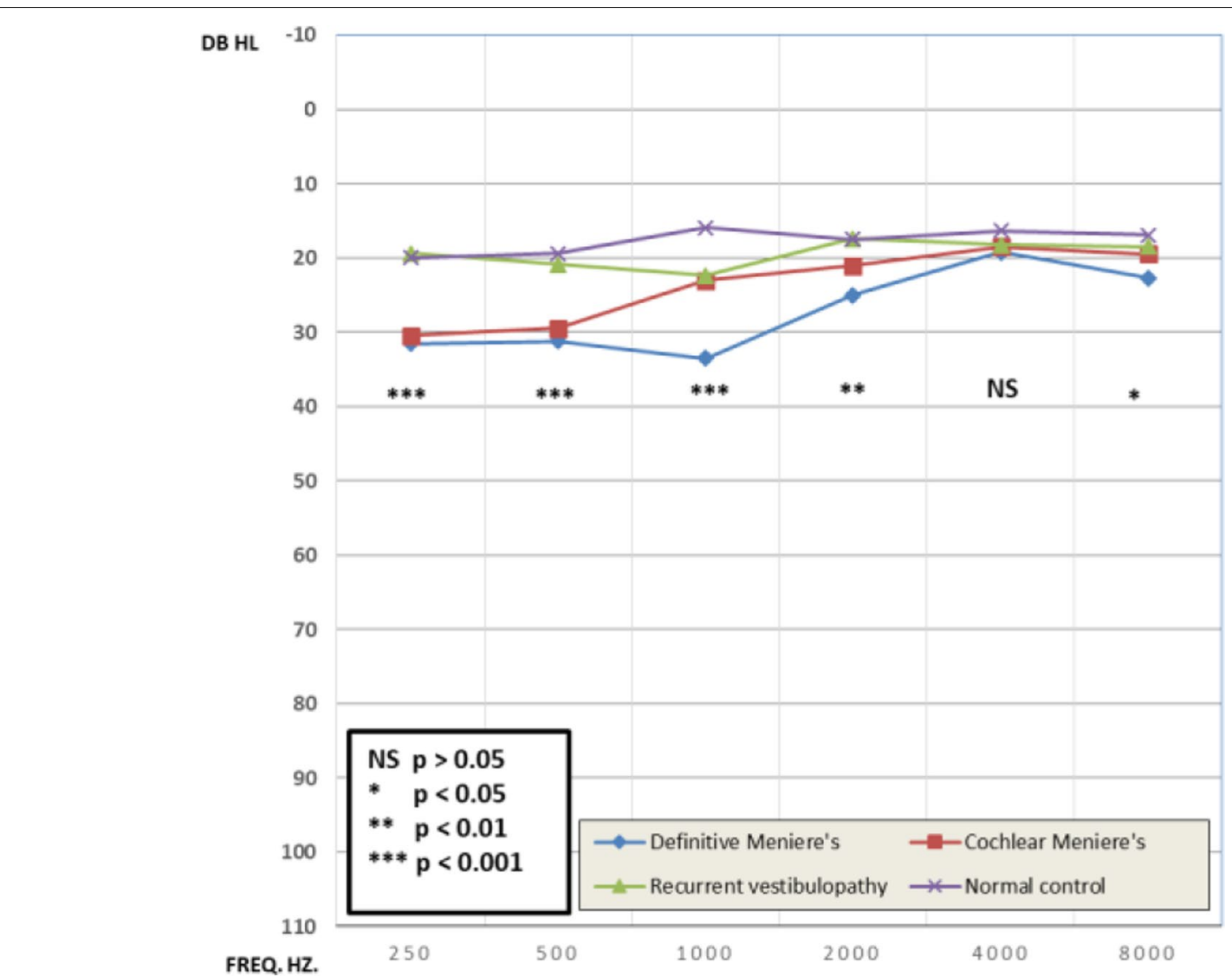

Fig. 2 RT ear audiogram, mean values

of the disease, and remission was spontaneous in most cases. All of which agreed with our results and did not contradict them [14]. Moreover, Huppert et al. found in a study that drop attacks were infrequent complications that spontaneously remitted in most cases [14].

In this study, unilateral affection was more in recurrent vestibulopathy group and cochlear Meniere's, while bilateral affection was more in the definitive Meniere's group. There was a significant difference among the groups with regard to laterality of the condition as shown in Fig. 1. These findings agreed with Niraj et al. who found that Meniere's disease usually starts confined to one ear but it often extends to involve both ears over time so that after 30 years, $50 \%$ of patients with Meniere's would have bilateral disease [15]. Meanwhile, Niraj et al. found that there was bilateral involvement in about $30 \%$ of the cases with Meniere's disease, which also agreed with our findings. While Wu et al. discussing the laterality of the disease has revealed that bilateral involvement was observed in about one-third of MD cases [16], saccular hydrops appeared to precede symptoms in bilateral MD patients, which also supports the findings in this study regarding the disease being bilateral over the course of time. On the other hand, Suh et al. also found the prevalence of bilateral disease was only $5.6 \%$. It was generally agreed that there was often minor symptoms on the other ear and also that it was rare that both ears were severely impacted [17].

It was shown that definitive Meniere's group had significantly longer duration than other groups as shown in Table 3 . This agreed with a study performed by Huppert et al. who found that the course of hearing loss seemed to show a considerable tendency to progress over the duration of the illness, which explained why definitive Meniere has longer duration, as it is the full-blown form of the disease [14].

After conventional audiological evaluation, it was found in the audiogram that there was mild to moderate affection in the definitive Meniere's group more than the other groups especially at 250, 500, and $1000 \mathrm{~Hz}$ frequencies. All cases of definitive Meniere's 13 (100\%) and cochlear Meniere's 10 (100\%) have had SNHL (Tables 4, 5, and 6). The right ear audiogram was significantly affected in the definitive Meniere's and the cochlear Meniere's groups than the recurrent vestibulopathy group especially at 250, 500, and $1000 \mathrm{~Hz}$ frequencies, as shown in Fig. 2. Moreover, the left ear audiogram was 


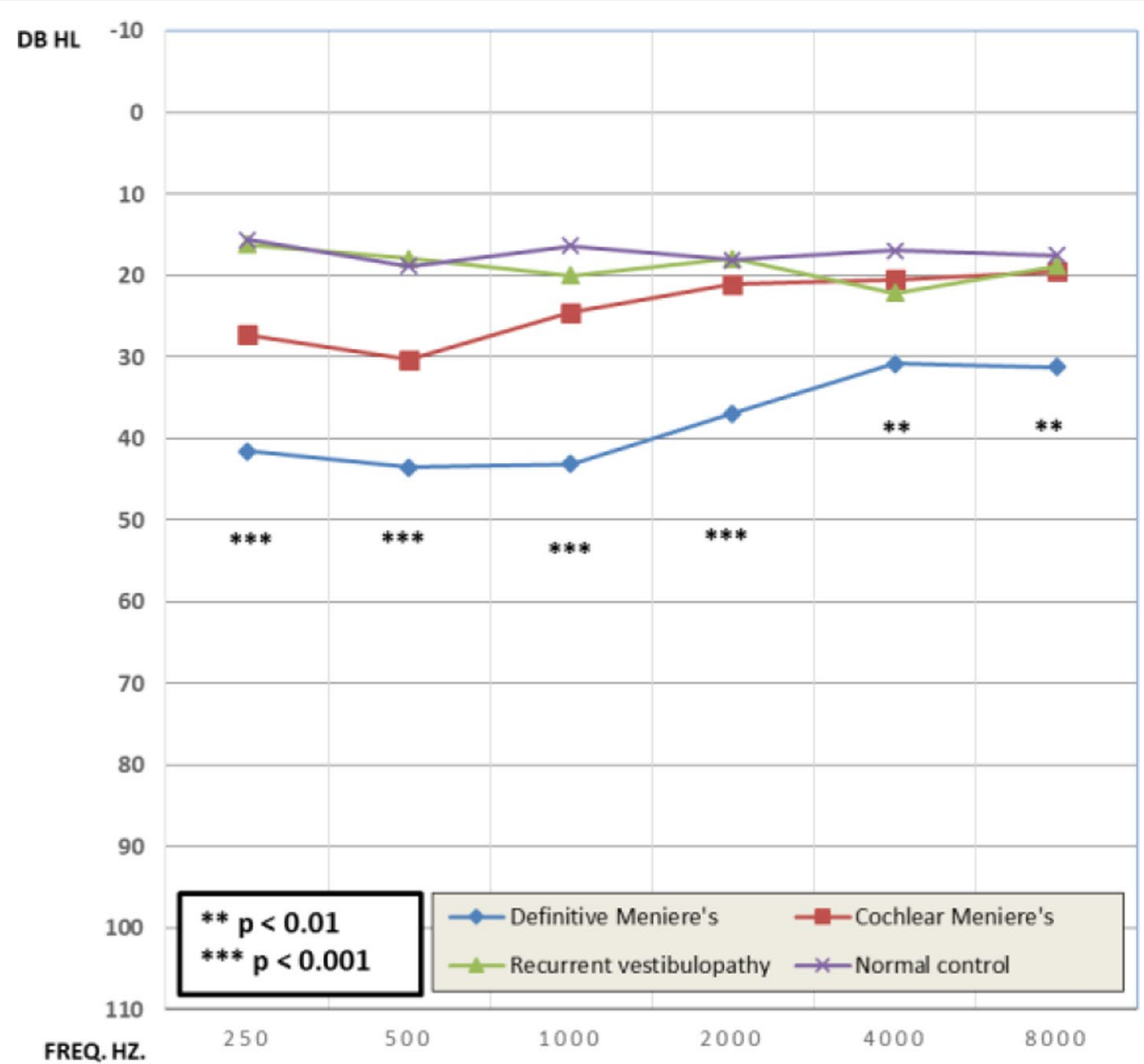

Fig. 3 Left ear audiogram, mean values. The left ear audiogram is significantly $(p<0.001)$ affected in the definitive Meniere's and the cochlear Meniere's groups than other group especially at $250,500,1000$, and $2000 \mathrm{~Hz}$ frequencies

Table 3 Duration of the disease

\begin{tabular}{llll}
\hline & Definitive Meniere's & Cochlear Meniere's & Recurrent vestibulopathy \\
\hline Mean & $27.5 \pm 22.8$ & $10.0 \pm 3.8$ & $13.8 \pm 6.0$ \\
Median (IQR) & $24.0(24.0 \%)$ & $12.0(6 \%)$ & $12.0(8.0)$ \\
\hline
\end{tabular}

Table 4 Pure tone audiogram abnormality in the three study groups

\begin{tabular}{llll}
\hline & $\begin{array}{l}\text { Definitive Meniere's, } \\
\boldsymbol{N}=\mathbf{1 3}\end{array}$ & $\begin{array}{l}\text { Cochlear Meniere's, } \\
\boldsymbol{N}=\mathbf{1 0}\end{array}$ & $\begin{array}{l}\text { Recurrent vestibulopathy, } \\
\boldsymbol{N}=\mathbf{1 7}\end{array}$ \\
\hline $\begin{array}{l}\text { Hearing loss, } \boldsymbol{n}(\%) \\
\text { SNHL }\end{array}$ & $13(100 \%)$ & $10(100 \%)$ & $0(0.0 \%)$ \\
No hearing loss & $0(0.0 \%)$ & $0(0.0 \%)$ & $0(0.0 \%)$ \\
\hline
\end{tabular}

significantly affected in the definitive Meniere's and the cochlear Meniere's groups than the recurrent vestibulopathy group especially at 250,500,1000, and $2000 \mathrm{~Hz}$ frequencies, as shown in Fig. 3. There was a high significant difference among the three groups regarding the left ear and right ear speech discrimination score. The scores were significantly lower in the definitive Meniere's group than both in cochlear Meniere's group and the recurrent vestibulopathy group, as shown in Table 7.These findings agreed with Taha et al. [18]. 
Table 5 PTA thresholds in different groups

\begin{tabular}{clllll}
\hline Hz & $\begin{array}{l}\text { Definitive } \\
\text { Meniere's }\end{array}$ & $\begin{array}{l}\text { Cochlear } \\
\text { Meniere's }\end{array}$ & $\begin{array}{l}\text { Recurrent } \\
\text { vestibulopathy }\end{array}$ & $\begin{array}{l}\text { Normal } \\
\text { control }\end{array}$ & $p$-value \\
\hline Right ear & & & & \\
250 & 31.5 & 30.5 & 19.4 & 20 & $<0.001$ \\
500 & 31.2 & 29.5 & 20.9 & 19.4 & $<0.001$ \\
1000 & 33.5 & 23 & 22.4 & 15.9 & $<0.001$ \\
2000 & 25 & 21 & 17.4 & 17.5 & $<0.01$ \\
4000 & 19.2 & 18.5 & 18.2 & 16.3 & $>0.05$ \\
8000 & 22.7 & 19.5 & 18.5 & 16.9 & $<0.05$ \\
Left ear & & & & \\
250 & 41.5 & 27.2 & 16.2 & 15.6 & $<0.001$ \\
500 & 43.5 & 30.3 & 17.9 & 18.8 & $<0.001$ \\
1000 & 43.1 & 24.5 & 20 & 16.3 & $<0.001$ \\
2000 & 36.9 & 21 & 17.9 & 18.1 & $<0.001$ \\
4000 & 30.8 & 20.5 & 22.1 & 16.9 & $<0.01$ \\
8000 & 31.2 & 19.5 & 18.8 & 17.5 & $<0.01$ \\
\hline Post hoc testing: *** $p$-value $0.001,{ }^{* *} p$-value $£ 0.01$ & & \\
\hline
\end{tabular}

Table 6 Comparison of PTA abnormality percent among the study groups

\begin{tabular}{|c|c|c|c|c|}
\hline $\mathrm{Hz}$ & Definitive Meniere's & Cochlear Meniere's & Recurrent vestibulopathy & $p$-value \\
\hline \multicolumn{5}{|c|}{ Right ear } \\
\hline 250 & $8(61.5 \%)$ & $8(80.0 \%)^{* *}$ & $1(5.9 \%)^{* * *}$ & $<0.001$ \\
\hline 500 & $8(61.5 \%)$ & $8(80.0 \%)^{* *}$ & $1(5.9 \%)^{* * *}$ & $<0.001$ \\
\hline 1000 & $8(61.5 \%)^{* * *}$ & $3(30.0 \%)$ & $0(0.0 \%)^{* * *}$ & 0.001 \\
\hline 2000 & $7(58.8 \%)^{* * *}$ & $1(10.0 \%)$ & $0(0.0 \%)^{* *}$ & 0.001 \\
\hline 4000 & $3(23.1 \%)$ & $1(10.0 \%)$ & $0(0.0 \%)$ & 0.113 \\
\hline 8000 & $4(30.8 \%)^{* *}$ & $0(0.0 \%)$ & $0(0.0 \%)$ & 0.01 \\
\hline \multicolumn{5}{|l|}{ Left ear } \\
\hline 250 & $11(84.6 \%)^{* * *}$ & $4(40.0 \%)$ & $0(0.0 \%)^{* * *}$ & $<0.001$ \\
\hline 500 & $11(84.6 \%)^{* * *}$ & $6(60.0 \%)$ & $0(0.0 \%)^{* * *}$ & $<0.001$ \\
\hline 1000 & $11(84.6 \%)^{* * *}$ & $3(30.0 \%)$ & $0(0.0 \%)^{* * *}$ & $<0.001$ \\
\hline 2000 & $10(76.9 \%)^{* * *}$ & $0(0.0 \%)$ & $0(0.0 \%)^{* *}$ & $<0.001$ \\
\hline 4000 & $5(38.5 \%)^{* * *}$ & $0(0.0 \%)$ & $0(0.0 \%)$ & 0.003 \\
\hline 8000 & $5(38.5 \%)^{* * *}$ & $0(0.0 \%)$ & $0(0.0 \%)$ & 0.003 \\
\hline
\end{tabular}

SNHL is significantly $(p<0.001)$ different in the study groups. Post hoc testing revealed that SNHL is significantly higher in definitive Meniere's $(p=0.001)$ and cochlear

Meniere's $(p=0.005)$ than in the recurrent vestibulopathy group

Table 7 Speech discrimination score

\begin{tabular}{|c|c|c|c|c|}
\hline Speech discrimination score & $\begin{array}{l}\text { Definitive Meniere's, } \\
N=13\end{array}$ & $\begin{array}{l}\text { Cochlear Meniere's, } \\
N=10\end{array}$ & $\begin{array}{l}\text { Recurrent vestibulopathy, } \\
N=17\end{array}$ & $p$-value \\
\hline Right ear, mean \pm SD & $93.2 \pm 6.6$ & $100.0 \pm 0.0$ & $99.8 \pm 1.0$ & $<0.001$ \\
\hline Left ear, mean \pm SD & $87.1 \pm 3.9$ & $96.4 \pm 2.3$ & $98.4 \pm 2.0$ & $<0.001$ \\
\hline
\end{tabular}

ECochG test is one of the most widely accepted tools in the diagnosis of endolymphatic hydrops. In this study, ECochG was done using the extratympanic Golden Triptodes. Evaluation of SP/AP ratio above the criterion level of abnormality (0.42) was according to the established norms of our clinic [18].

Our study revealed that there was a highly significant difference in the mean left ear SP/AP ratio between groups. It was also found that there was a significant difference between definitive and cochlear Meniere's and between the definitive Meniere's group and the recurrent vestibulopathy group, as shown in Table 8 . To the best of the author's knowledge, no study compared among the three types of endolymphatic hydrops regarding the EcochG.

In Ménière's disease, there is elevated endolymphatic pressure and distention. The baseline shift is caused by bowing of Reissner's membrane and displacement of basilar membrane. So this asymmetry causes elevation of the SP/AP ratio, as the SP is elevated asymmetrically more than the AP [18]. These findings were also supported by a study done by Tawfik et al., in which ECochG, VEMP, and VNG were performed in patients with Meniere's disease, and 78\% of patients showed abnormal cVEMP response [19]. 
Table 8 Electrocochleography SP/AP ratio in different groups

\begin{tabular}{llll}
\hline & $\begin{array}{l}\text { Definitive Meniere's, } \\
\mathbf{N = 1 3}\end{array}$ & $\begin{array}{l}\text { Cochlear Meniere's, } \\
\mathbf{N = 1 0}\end{array}$ & $\begin{array}{l}\text { Recurrent vestibulopathy, } \\
\mathbf{N = 1 7}\end{array}$ \\
\hline RT ear, mean \pm SD & $0.43 \pm 0.18$ & $0.45 \pm 0.08$ & $0.48 \pm 0.19$ \\
RT ear, normal & $8(61.5 \%)$ & $5(50.0 \%)$ & $11(64.4 \%)$ \\
RT ear, abnormal, number (\%) & $5(38.5 \%)$ & $5(50.0 \%)$ & $6(35.6 \%)$ \\
LT ear, mean \pm SD & $0.70 \pm 0.07$ & $0.48 \pm 0.15$ & $0.54 \pm 0.13$ \\
LT ear, normal & $3(15.4 \%)$ & $3(30.0 \%)$ & $7(41.2 \%)$ \\
LT ear, abnormal, number (\%) & $11(84.6 \%)$ & $7(70.0 \%)$ & $10(58.8 \%)$ \\
\hline
\end{tabular}

All cases showed no spontaneous nystagmus with normal oculomotor function and Dix-Hallpike maneuver. Positional nystagmus and caloric test was comparable among all study groups as shown in Table 9. Huppert in a study that greed with us revealed that caloric hyporesponsiveness and duration of the disease seemed to be correlated [14]. It was found that caloric excitability deteriorates mainly in the first years, and then it either increases only slightly or remains stable. A functional reduction of about $35-50 \%$ of caloric response was commonly found in the affected ear. Only a few patients had a more severe decrement of vestibular function, and the absence of caloric responses was rare, which agreed with our findings as per the caloric findings which were usually normal [14]. It is well known that caloric test is the measure of the function of lateral SCC and as EH usually affects pars inferior, which is located in cochlea and saccule, caloric test usually shows no abnormality in $\mathrm{EH}[19]$.

Asymmetric response of C-VEMP was seen in nine (69.2\%) of definitive Meniere's cases, in 14 (82.4\%) of recurrent vestibulopathy cases, and only in three $(30 \%)$ of cochlear Meniere's cases as shown in Table 10. These findings agreed with the findings of Young et al. who reported that the IAD ratio of VEMPs correlates with the stage of Ménière's disease and can be used as another aid to assess the stage of Ménière's disease [20].

There was a high and significant difference in the mean amplitude of c-VEMP among the groups. Multiple comparisons revealed a significant difference between definitive Meniere's and normal group and between the recurrent vestibulopathy disease group and the normal group as shown in Table 11. These findings agreed with Niraj et al., in a study identifying endolymphatic hydrops in Meniere's disease using cVEMP. The results revealed significantly smaller peak-to-peak amplitude of cVEMP in the Meniere's group compared to the healthy controls. This might be attributed to the changes observed at the vestibular periphery, especially the saccule [15]. Niraj et al. agreed with our findings in a study that revealed that the lowest amplitudes were obtained in the affected ears with Meniere's disease followed by their unaffected
Table 9 Positional nystagmus and the asymmetric caloric test

\begin{tabular}{llll}
\hline & MD & CM & RV \\
\hline Normal & $7(53.8 \%)$ & $7(70 \%)$ & $8(47.7 \%)$ \\
Abnormal & $6(46.1 \%)$ & $3(30 \%)$ & $11(64.7 \%)$ \\
Positional nystagmus & $6(46.2 \%)$ & $3(30 \%)$ & $9(52.9 \%)$ \\
A symmetric caloric test & $2(15.4 \%)$ & $0(0 \%)$ & $2(11.8 \%)$ \\
\hline
\end{tabular}

ears. The individuals with Meniere's disease also portrayed larger asymmetry ratios than their healthy counterparts, and the results revealed significantly smaller amplitude of cVEMP even in the unaffected ears of individuals with Meniere's disease when compared to age and gender of matched healthy individuals group. The histopathological studies in individuals with Meniere's disease have revealed severe hydrops, resulting in the distortion of the saccule or even rupture of the saccular membrane. This distorted or ruptured saccular membrane was likely to affect the mechanical energy transfer that vibrates the saccular macula and stimulates the saccular hair cells. This was therefore likely to result in reduced amplitude on the affected side of individuals with Meniere's disease [15].

There was a significant difference in $\mathrm{p} 1$ and $\mathrm{n} 1$ latencies in the right ear between the study groups. It was shown that in the right ear P1 latency, the difference was among recurrent vestibulopathy and both definitive Meniere's and cochlear Meniere's. In addition, in the right ear N1 latency, the difference was among recurrent vestibulopathy and both definitive Meniere's and cochlear Meniere's as shown in Table 11.

In this study, low amplitude of o-VEMP was seen in $11(84.6 \%)$ of definitive Meniere's cases, 9 (90\%) of cochlear Meniere's cases, 15 (88.2\%) of recurrent vestibulopathy cases, and only two (25\%) of normal cases as seen in Figs. 4 and 5. Santos et al. agreed with our findings in a study examining the ocular vestibular evoked myogenic potentials in response to air conducted sound in Meniere's disease; it was found that it was lower in patients with MD response. Also, thresholds were higher 
Table 10 Cervical vestibular evoked myogenic potentials normal and abnormal cases

\begin{tabular}{|c|c|c|c|c|}
\hline & Definitive Meniere's & Cochlear Meniere's & Recurrent vestibulopathy & $p$-value \\
\hline Abnormal, $n(\%)$ & $9(69.2 \%)$ & $3(30 \%)$ & $14(82.4 \%)$ & $<0.001$ \\
\hline Normal, $n(\%)$ & $4(30.8 \%)$ & $7(70 \%)$ & $3(17.6 \%)$ & \\
\hline Mean + SD & $0.39 \pm 0.19$ & $0.24 \pm 0.12$ & $0.34 \pm 0.10$ & $<0.001$ \\
\hline
\end{tabular}

Table 11 c-VEMP P1 and N1 latencies in the left and right ear

\begin{tabular}{lllll}
\hline & Definitive Meniere's & Cochlear Meniere's & Recurrent vestibulopathy & $\boldsymbol{p}$-value \\
\hline Right ear P1 latency & $11.4 \pm 5.3$ & $8.9 \pm 3.5$ & $19.3 \pm 4.0$ & $<0.001$ \\
Right ear N1 latency & $16 \pm 7.6$ & $18.7 \pm 5.4$ & $24.6 \pm 2.5$ & $<0.001$ \\
Left ear P1 latency & $14.1 \pm 6.2$ & $12.4 \pm 3.8$ & $11.7 \pm 2.5$ & 0.051 \\
Left ear N1 latency & $22.1 \pm 6.2$ & $16.7 \pm 8.4$ & $19.4 \pm 6.6$ & 0.062 \\
\hline
\end{tabular}

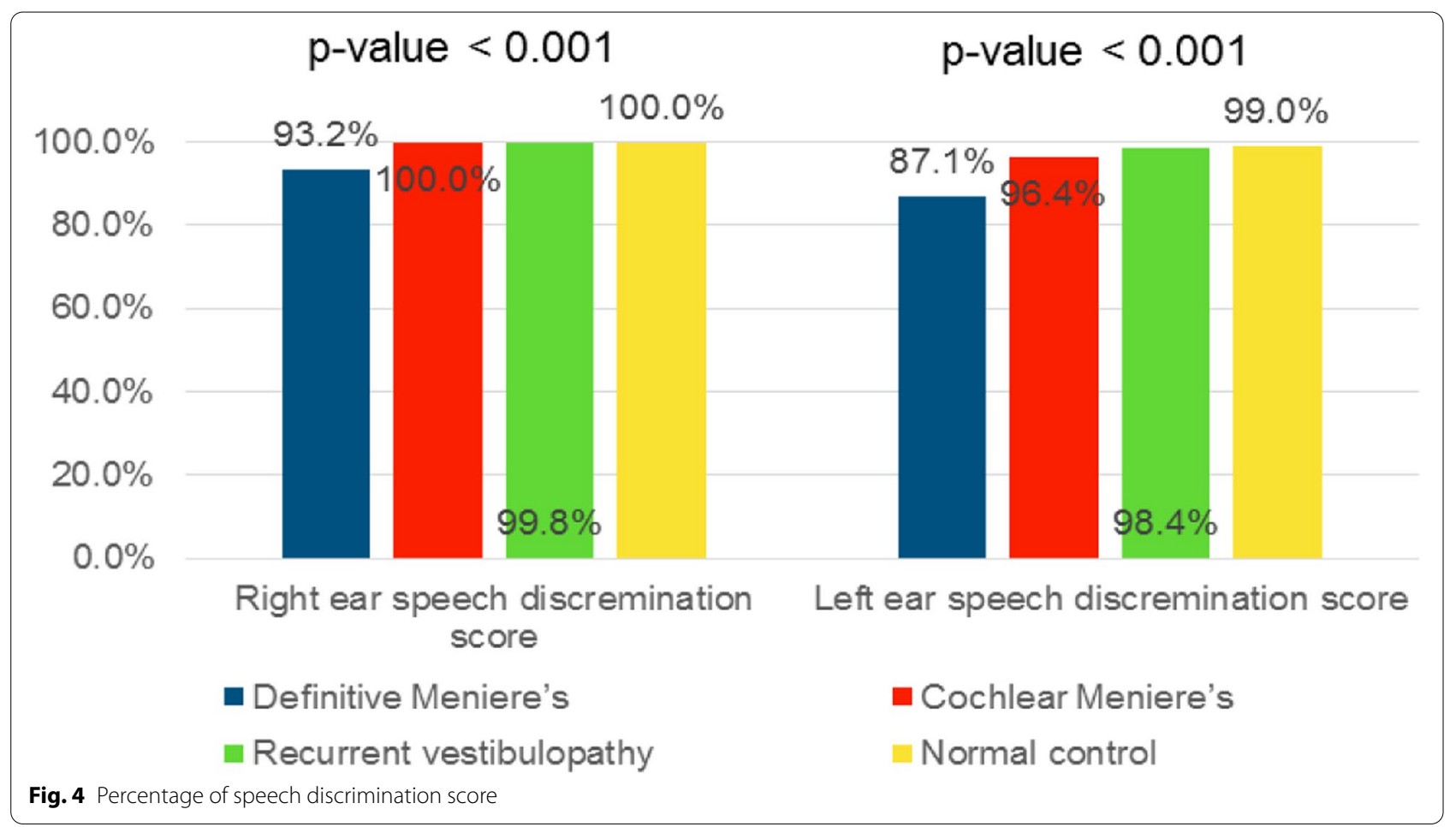

than in subjects not having MD. The affected ear was more altered than the clinically unaffected ear. Therefore, the air conducted VEMP could be a relevant addition to the diagnosis workup of patients with possible MD. A lower response rate, smaller amplitude, and higher threshold of the oVEMP indicated the pathological disease evidence.

Latencies of $\mathrm{n} 1$ and $\mathrm{p} 1$ were measured in right and left ear in all cases. There is a significant difference in right ear p1 and left ear p1 latencies among the study groups, as shown in Table 11. Also, there were significant differences among the study groups and the control group for most of the wave parameters in combined cervical and ocular vestibular myogenic potentials. There was a significant positive strong correlation between age and ECochG SP/AP ratio left ear, OVEMP IAD, and OVEMP left ear N1. In addition, there is a significant positive correlation between duration and ECochG SP/AP ratio left ear and CVEMP left ear N1, as shown in Table 8. Those findings agreed with the same study made by Santos et al. [21] (Fig. 6). 

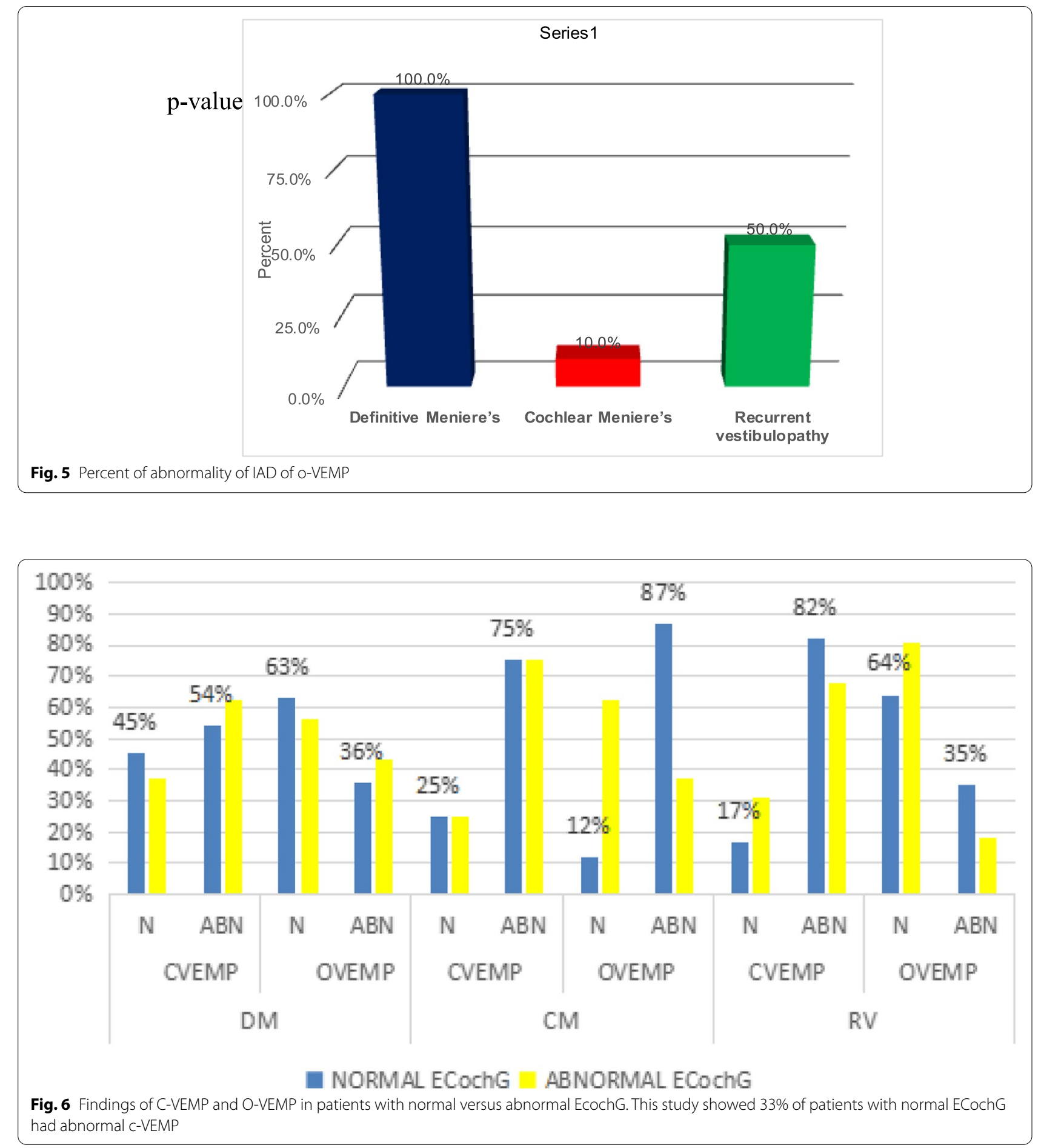

Endolymphatic hydrops is more commonly observed in pars inferior resulting in bowing of Reissner's membrane and distention of the saccule and pars superior is least commonly affected. Accordingly, ECochG and
C-VEMP are more sensitive in the diagnosis of EH. Ocular VEMP was the least sensitive test in the diagnosis of all types of endolymphatic hydrops. Cervical VEMP had moderate sensitivity in diagnosis of 
Table 12 Percentage of abnormal IAD of c-VEMP

\begin{tabular}{lllll}
\hline & DMD & CMD & RV & $p$-value \\
\hline Abnormal o-VEMP IAD, $n(\%)$ & $7(53 \%)$ & $3(30.0 \%)$ & $10(58 \%)$ & 0.028 \\
Normal o-VEMP IAD, $n(\%)$ & $6(46 \%)$ & $7(70.0 \%)$ & $7(41 \%)$ & \\
\hline
\end{tabular}

Table 13 o-VEMP P1 and N1 latencies in the left and right ear

\begin{tabular}{|c|c|c|c|c|}
\hline & $\begin{array}{l}\text { Definitive } \\
\text { Meniere's }\end{array}$ & $\begin{array}{l}\text { Cochlear } \\
\text { Meniere's }\end{array}$ & $\begin{array}{l}\text { Recurrent } \\
\text { vestibulopathy }\end{array}$ & $p$-value \\
\hline $\begin{array}{l}\text { Right ear P1 } \\
\text { latency }\end{array}$ & $13.0 \pm 1.3$ & $13.9 \pm 1.7$ & $16.1 \pm 0.1$ & 0.007 \\
\hline $\begin{array}{l}\text { Right ear N1 } \\
\text { latency }\end{array}$ & $10.2 \pm 0.1$ & $11.2 \pm 1.5$ & $12.0 \pm 0.1$ & 0.237 \\
\hline $\begin{array}{l}\text { Left ear P1 } \\
\text { latency }\end{array}$ & $13.6 \pm 0.8$ & $15.2 \pm 0.9$ & $14.5 \pm 2.2$ & 0.027 \\
\hline $\begin{array}{l}\text { Left ear N1 } \\
\text { latency }\end{array}$ & $11.5 \pm 0.5$ & $11.0 \pm 0.2$ & $10.6 \pm 1.4$ & 0.097 \\
\hline
\end{tabular}

Table 14 o-VEMP P1 and N1 latencies and abnormalities in the left and right ear

\begin{tabular}{lccll}
\hline & $\begin{array}{l}\text { Definitive } \\
\text { Meniere's }\end{array}$ & $\begin{array}{l}\text { Cochlear } \\
\text { Meniere's }\end{array}$ & $\begin{array}{l}\text { Recurrent } \\
\text { vestibulopathy }\end{array}$ & $\boldsymbol{p}$-value \\
\hline $\begin{array}{l}\text { Abnormal } \\
\text { O-VEMP }\end{array}$ & $11(84.6 \%)$ & $9(90.0 \%)$ & $15(88.2 \%)$ & 0.002 \\
$\begin{array}{l}\text { Normal } \\
\text { o-VEMP }\end{array}$ & $2(15.4 \%)$ & $1(10.0 \%)$ & $2(11.8 \%)$ & \\
$\begin{array}{l}\text { Right ear } \\
\text { P1 latency }\end{array}$ & $13.0 \pm 1.3$ & $13.9 \pm 1.7$ & $16.1 \pm 0.1$ & 0.007 \\
$\begin{array}{l}\text { Right ear } \\
\text { N1 latency }\end{array}$ & $10.2 \pm 0.1$ & $11.2 \pm 1.5$ & $12.0 \pm 0.1$ & 0.237 \\
$\begin{array}{l}\text { Left ear P1 } \\
\text { latency }\end{array}$ & $13.6 \pm 0.8$ & $15.2 \pm 0.9$ & $14.5 \pm 2.2$ & 0.027 \\
$\begin{array}{l}\text { Left ear N1 } \\
\text { latency }\end{array}$ & $11.5 \pm 0.5$ & $11.0 \pm 0.2$ & $10.6 \pm 1.4$ & 0.097 \\
\hline
\end{tabular}

Table 15 Abnormal IAD of O-VEMP. Post hoc Bonferroni for multiple comparisons revealed a significant difference between definitive and cochlear Meniere's as regards o-VEMP IAD ( $p$-value $=0.032$ ) only

\begin{tabular}{lllll}
\hline & DMD & CMD & RV & -value \\
\hline $\begin{array}{l}\text { Abnormal o-VEMP IAD, } \\
\begin{array}{l}\text { (\%) } \\
\text { O-VEMP IAD, mean } \\
\pm \text { SD }\end{array}\end{array}$ & $0.39 \pm 0.08$ & $0.17 \pm 0.06$ & $0.35 \pm 0.07$ & 0.018 \\
\hline
\end{tabular}

Table 16 Duration of symptoms in relation to laterality

\begin{tabular}{llll}
\hline & Unilateral & Bilateral & $\boldsymbol{p}$ \\
\hline Mean & $13.1 \pm 5.8$ & $26.2 \pm 23.5$ & 0.068 \\
Median (IQR) & $12.0(2.0 \%)$ & $12.0(24 \%)$ & \\
\hline
\end{tabular}

Mann-Whitney U

Table 17 Correlations between age, duration of the disease, and all test findings

\begin{tabular}{|c|c|c|c|c|}
\hline & \multicolumn{2}{|l|}{ Age } & \multicolumn{2}{|l|}{ Duration } \\
\hline & $\begin{array}{l}\text { Correlation } \\
\text { coefficient }\end{array}$ & $p$-value & $\begin{array}{l}\text { Correlation } \\
\text { coefficient }\end{array}$ & $p$-value \\
\hline $\begin{array}{l}\text { ECochG SP/AP ratio } \\
\text { right ear }\end{array}$ & -0.17 & 0.305 & 0.27 & 0.096 \\
\hline $\begin{array}{l}\text { ECochG SP/AP ratio } \\
\text { left ear }\end{array}$ & $0.51^{* *}$ & 0.001 & $0.34^{*}$ & 0.03 \\
\hline OVEMPIAD & $0.91^{* *}$ & 0.002 & 0.66 & 0.073 \\
\hline CVEMP IAD & 0.12 & 0.477 & 0.25 & 0.121 \\
\hline OVEMP right ear N1 & -0.48 & 0.233 & 0.08 & 0.858 \\
\hline OVEMP right ear $\mathrm{P} 1$ & 0.05 & 0.91 & 0.27 & 0.511 \\
\hline OVEMP left ear N1 & $0.75^{*}$ & 0.033 & 0.36 & 0.382 \\
\hline OVEMP left ear P1 & 0.1 & 0.821 & 0.03 & 0.952 \\
\hline CVEMP right ear N1 & -0.08 & 0.62 & -0.07 & 0.671 \\
\hline CVEMP right ear P1 & 0.07 & 0.672 & 0.16 & 0.319 \\
\hline CVEMP left ear N1 & 0.22 & 0.18 & $0.42^{* *}$ & 0.007 \\
\hline CVEMP left ear P1 & -0.04 & 0.823 & 0.16 & 0.315 \\
\hline
\end{tabular}

definitive Meniere's disease, but low sensitivity in both cochlear Meniere and recurrent vestibulopathy. Electrocochleography was the most sensitive test in diagnosis of all types of endolymphatic hydrops. In definitive Meniere's disease, about more than half of the patients had abnormal cVEMP and about more than half of the patients had normal oVEMP. However, in cochlear Meniere's disease, most of the patients had abnormal cVEMP, and more than half of the patients had normal oVEMP. Moreover, in recurrent vestibulopathy, more than half of the patients had abnormal cVEMP, and most of the patients had normal oVEMP. To the best of author's knowledge, no study compared the three tests in different categories of endolymphatic hydrops (Tables 12, 13, 14, 15, 16, 17, and 18).

\section{Conclusions}

1) Electrocochleography is the most sensitive test in the diagnosis of all types of endolymphatic hydrops. 
Table 18 Sensitivity and specificity of c-VEMP, o-VEMP, and ECochG

\begin{tabular}{|c|c|c|c|c|c|c|}
\hline & \multicolumn{2}{|l|}{ EcochG } & \multicolumn{2}{|l|}{ c-VEMP } & \multicolumn{2}{|c|}{ o-VEMP } \\
\hline & SEN & SPEC & SEN & SPEC & SEN & SPEC \\
\hline \multirow[t]{2}{*}{ DMD } & $84.60 \%$ & $1000 \%$ & $15.40 \%$ & $75.00 \%$ & $53.80 \%$ & $12.50 \%$ \\
\hline & $(11 / 13)$ & $(8 / 8)$ & $(2 / 13)$ & $(6 / 8)$ & $(7 / 13)$ & $(1 / 8)$ \\
\hline \multirow[t]{2}{*}{ CMD } & $90.00 \%$ & $100.00 \%$ & $10.00 \%$ & $75.00 \%$ & $10.00 \%$ & $12.50 \%$ \\
\hline & $(9 / 10)$ & $(8 / 8)$ & $(1 / 10)$ & $(6 / 8)$ & $(1 / 10)$ & $(1 / 8)$ \\
\hline \multirow[t]{2}{*}{ RV } & $82.40 \%$ & $100.00 \%$ & $5.90 \%$ & $75.00 \%$ & $17.60 \%$ & $12.50 \%$ \\
\hline & $(14 / 17)$ & $(8 / 8)$ & $(1 / 17)$ & $(6 / 8)$ & $(3 / 17)$ & $(1 / 8)$ \\
\hline \multirow[t]{2}{*}{ All } & $85.00 \%$ & $100.00 \%$ & $10.00 \%$ & $75.00 \%$ & $27.50 \%$ & $37.50 \%$ \\
\hline & $(34 / 40)$ & $(8 / 8)$ & $(4 / 40)$ & $(6 / 8)$ & $(11 / 40)$ & $(3 / 8)$ \\
\hline
\end{tabular}

2) Ocular VEMP is the least sensitive test in the diagnosis of all types of endolymphatic hydrops.

3) Cervical VEMP has moderate sensitivity in the diagnosis of definitive Meniere's disease, but low sensitivity in both cochlear Meniere and recurrent vestibulopathy.

\section{Abbreviations}

EcochG: Electrocochleography;VEMP: Vestibular evoked myogenic potentials; C-VEMP: Cervical vestibular evoked myogenic potentials; O-VEMP: Ocular vestibular evoked myogenic potentials; PTA: Pure tone audiometry.

\section{Acknowledgements}

None

\section{Authors' contributions}

H.T and T.A: the idea of the research, collecting cases, and testing. I.N and M. A.: analysis of the results and data processing, revision, and writing. The authors read and approved the final manuscript.

\section{Funding}

None

\section{Availability of data and materials}

The datasets used and/or analysed during the current study are available from the corresponding author on reasonable request.

\section{Declarations}

Ethics approval and consent to participate

Ethical committee of Ain Shams University No 13242. Consent obtained from study participants before research: informed written consent is available.

\section{Consent for publication}

Not applicable as no data of patients were published

\section{Competing interests}

The authors declare that they have no competing interests.

\section{Author details}

'Department of ENT: Audiology Unit, Faculty of Medicine, Ain Shams University, Villa $4 \backslash 7 \mathrm{E}$, Compound Calimera, Shorouk City, Cairo, Egypt. ${ }^{2}$ Department of ENT, Faculty of Medicine, MUST University, 6th of October City, Egypt. ${ }^{3}$ Department of ENT: Audiology Unit, Faculty of Medicine, MUST University, 6th of October City, Egypt.
Received: 29 September 2021 Accepted: 26 November 2021 Published online: 24 January 2022

\section{References}

1. Ciuman RR (2013) Inner ear symptoms and disease: pathophysiological understanding and therapeutic options. Med Sci Monit 19:1195-1210

2. Berlinger NT (2011) Ménière's disease: new concepts, new treatments. Minn Med 94:33-36

3. Gürkov R, Pyykö I, Zou J, Kentala E (2016) What is Ménière's disease? A contemporary re-evaluation of endolymphatic hydrops. J Neurol 263(Suppl 1):S71-S81

4. Zhang Y, Liu B, Wang R, Jia R, Gu X (2016) Characteristics of the cochlear symptoms and functions in Meniere's disease. Chin Med J 129(20):2445

5. Paparella MM (1985) The cause (multifactorial inheritance) and pathogenesis (endolymphatic malabsorption) of Meniere's disease and its symptoms (mechanical and chemical). Acta Otolaryngol 99(3-4):445-451

6. Rosengren SM, Colebatch JG, Young AS, Govender S, Welgampola MS (2019) Vestibular evoked myogenic potentials in practice: methods, pitfalls and clinical applications. Clin Neurophysiol Pract 4:47-68

7. Curthoys IS, Vulovic V, Manzari L (2012) Ocular vestibular-evoked myogenic potential (OVEMP) to test utricular function: neural and oculomotor evidence. Acta Otorhinolaryngol Ital 32:41-45

8. (1995) AAO-HNS Committee on hearing and equilibrium guidelines for the diagnosis and evaluation of therapy in Meniere's disease. American Academy of Otolaryngology-Head and Neck Foundation, Inc. Otolaryngol Head Neck Surg 113(3):181-185

9. Park SN, Park KH, Im DJ, Kim JH, Kim JY, Yeo SW (2006) RV: clinical characteristics and efficacy of combination therapy. J Korean Balance Society 5(2):262-268

10. Schaaf $\mathrm{H}$, Hesse $\mathrm{G}$ (2007) Low frequency fluctuating hearing loss without labyrinthine vertigo--a genuine disease? A follow up study after 4 and 10 years. HNO 55(8):630

11. Simo H, Yang S, Qu W, Preis M, Nazzal M, Baugh R (2015) Ménière's disease: importance of socioeconomic and environmental factors. Am J Otolaryngol 36(3):393-398

12. Requena T, Espinosa-Sanchez JM, Cabrera S, Trinidad G, Soto-Varela A, Santos-Perez S, Aran I (2014) Familial clustering and genetic heterogeneity in Meniere's disease. Clin Genet 85(3):245-252

13. Lopez-Escamez JA, Carey J, Chung WH, Goebel JA, Magnusson M, Mandalà M et al (2015) Diagnostic criteria for Ménière's disease. J Vestib Res 25(1):1-7

14. Huppert D, Strupp M, Brandt T (2010) Long-term course of Meniere's disease revisited. Acta Otolaryngol 130(6):644-651

15. Niraj SK, Krishnamurthy R, Premkumar PK (2015) Relative efficiency of cochlear hydrops analysis masking procedure and cervical vestibular evoked myogenic potential in identification of Meniere's disease. Adv Otolaryngol:1-12 
16. Wu CH, Murofushi T (1999) The effect of click repetition rate on vestibular evoked myogenic potential. Acta Otolaryngol 119(1):29-32

17. Suh MJ, Jeong J, Kim HJ, Jung J, Kim SH (2018) Clinical characteristics of bilateral Meniere's disease in a single Asian ethnic group. Laryngoscope. https://doi.org/10.1002/lary.27423

18. Taha H, El-Gohary M, Kamal N, El-Kahky A (2000) Vestibulo-cochlear response to glycerol in Meniere's patients. Meniere's disease-update. Proceedings of the 4th International Symposium on Meniere's disease, Paris, pp 265-274

19. Tawfik S, Shalaby AA, NaeimF (2002) Diagnostic value of vestibular evoked myogenic potentials in Meniere's disease. Unpublished master Thesis, Ain Shams University

20. Young YH, Huang TW, Cheng PW (2002) Vestibular evoked myogenic potentials in delayed endolymphatic hydrops. Laryngoscope 112(9):1623-1626

21. Santos MAR, Silva TR, Resende LMD (2017) Combined ocular and cervical vestibular evoked myogenic potential in individuals with vestibular hyporeflexia and in patients with Ménière's disease. Br J Otorhinolaryngol 83(3):330-340

\section{Publisher's Note}

Springer Nature remains neutral with regard to jurisdictional claims in published maps and institutional affiliations.

\section{Submit your manuscript to a SpringerOpen ${ }^{\circ}$ journal and benefit from:}

- Convenient online submission

- Rigorous peer review

- Open access: articles freely available online

- High visibility within the field

- Retaining the copyright to your article

Submit your next manuscript at $\boldsymbol{\nabla}$ springeropen.com 